
$\mathrm{XVI})$

\title{
Las paletas de calero de la costa central durante el Horizonte Tardío (1440-1532 d. C.)
}

Les spatules de chaulage de l'Horizon récent sur la c

te centrale (1440-1532 ap. J.-C.)

The Late Horizon lime pallets of the central coast (AD 1440-1532)

Luis Enrique Castillo Narrea

\section{OpenEdition \\ Journals}

\section{Edición electrónica}

URL: http://journals.openedition.org/bifea/8409

DOI: $10.4000 /$ bifea.8409

ISSN: 2076-5827

Editor

Institut Français d'Études Andines

Edición impresa

Fecha de publicación: 1 abril 2017

Paginación: 267-290

ISSN: 0303-7495

Referencia electrónica

Luis Enrique Castillo Narrea, «Las paletas de calero de la costa central durante el Horizonte Tardío (1440-1532 d. C.) », Bulletin de l'Institut français d'études andines [En línea], 46 (1) | 2017, Publicado el 08 abril 2017, consultado el 06 noviembre 2020. URL : http://journals.openedition.org/bifea/8409; DOI : https://doi.org/10.4000/bifea.8409

\section{cc)}

Les contenus du Bulletin de l'Institut français d'études andines sont mis à disposition selon les termes de la licence Creative Commons Attribution - Pas d'Utilisation Commerciale - Pas de Modification 4.0 International. 


\title{
Las paletas de calero de la costa central durante el Horizonte Tardío (1440-1532 d. C.)
}

\author{
Luis Enrique Castillo Narrea*
}

\section{Resumen}

En la colección de metales del Museo Nacional de Arqueología, Antropología e Historia del Perú (MNAAHP) se ha identificado un grupo de objetos de ajuares funerarios como paletas de calero que estarían relacionados con el consumo de hojas de coca. El objetivo del presente análisis es caracterizar la tipología, las aleaciones, las técnicas de manufactura empleadas en las piezas y la relación de estas con el género de los individuos enterrados. Para complementar la investigación y a solicitud de la dirección del museo durante el año 2014, se realizó un tratamiento conservativo para que pueda ser expuesto.

Para tal fin, se seleccionó un corpus de doce paletas de calero procedentes de contextos arqueológicos de la costa central de los sitios de Rinconada, Isla San Lorenzo y Armatambo asociados al Horizonte Tardío. El estudio de los contextos y la comparación con instrumentos similares procedentes de los sitios de Pachacamac, Huaca de la Luz, Inca Uyu, Machu Picchu y Túcume nos aproximará a la relación de los metales y de las técnicas con el género de los individuos. Los análisis macroscópicos y radiográficos nos ayudarán a comprender la composición y las técnicas de elaboración. Las paletas de calero al parecer fueron empleadas en ritos chamánicos. Las aleaciones de plata y las representaciones ornitomorfas están asociadas con individuos masculinos mientras que las aleaciones de cobre y las representaciones esféricas están asociadas con individuos femeninos.

Palabras clave: paleta, calero, Rinconada, Armatambo, San Lorenzo, coca

\section{Les spatules de chaulage de l'Horizon récent sur la côte centrale (1440-1532 ap. J.-C.)}

\section{Resumé}

Dans un groupe d'objets provenant de mobiliers funéraires de la collection de métaux du Museo Nacional de Arqueología, Antropología e Historia del Perú (MNAAHP), nous avons identifié des

* Coordinador del Grupo de Restauración Latinoamericano de Metales, Lima, Perú. Email: grlmetales@gmail.com 
spatules de chaulage, supposées être liées à la consommation de feuilles de coca. Ce travail a pour but la caractérisation des typologies, des alliages et des techniques de fabrication des pièces ainsi que la recherche d'un rapport entre ces caractéristiques et le genre des individus enterrés. Suite à une demande émise en 2014 par la direction du musée, un traitement de conservation a été réalisé sur les pièces pour qu'elles puissent être exposées.

Pour ce faire, un corpus de douze spatules de chaulage provenant de contextes archéologiques datant de I'Horizon récent, des sites de Rinconada, Isla San Lorenzo et Armatambo, situés sur la côte centrale, a été sélectionné. Afin de mieux comprendre la composition et les techniques de fabrication, nous avons procédé à des examens macroscopiques et radiographiques. L'étude des contextes et la comparaison avec des objets similaires provenant des sites de Pachacamac, Huaca de la Luz, Inca Uyu, Machu Picchu et Túcume, nous a permis de faire le rapport entre métaux et techniques et le genre de l'individu. Les spatules de chaulage semblent avoir été employées pendant les rites chamaniques. Les alliages d'argent et les représentations ornithomorphes sont associés aux individus masculins, tandis que les alliages de cuivre et les représentations sphériques sont associés aux individus féminins.

Mots-clés : spatule, chaulage, Rinconada, Armatambo, San Lorenzo, coca

\title{
The Late Horizon lime pallets of the central coast (AD 1440-1532)
}

\begin{abstract}
A group of objects from burials, belonging to the metals collection of the Museo Nacional de Arqueología, Antropología e Historia del Perú (MNAAHP), were identified as lime pallets, related to the consumption of coca leaves. The aim of this work is to describe their typology, alloys and the manufacturing technologies employed, as well as to define the relation between these characteristics and the gender of the buried individual. This study is completed by a description of the conservation treatment that was applied in 2014 at the request of the museum direction.

A corpus consisting of twelve contextualized Late Horizon lime pallets from the sites of Rinconada, Isla San Lorenzo and Armatambo, located on the central coast of Peru, was selected. Macroscopic and radiographic exams were carried out to better understand the composition and the manufacture techniques employed. The study of the contexts and the comparison with similar objects from the sites of Pachacamac, Huaca de la Luz, Inca Uyu, Machu Picchu and Túcume shed new light on the relation between alloys and techniques and the individual's gender. Lime palettes were apparently used during shamanic rituals. The silver alloys with ornithomorphe representations were associated with male individuals while pallets made of copper alloys with spherical representation were associated with female individuals.
\end{abstract}

Keywords: palette, liming, Rinconada, Armatambo, San Lorenzo, coca

\section{INTRODUCCIÓN}

La independización de grupos sociales regionales al decaer el control de la cultura Wari, la formación de centros urbanos donde se cohesiona el poder político y religioso, el crecimiento demográfico, la masificación de la producción alfarera y textil, el desarrollo lítico y orfebre controlados por las élites locales fueron fenómenos que definieron el Periodo Intermedio Tardío (900-1440 d. C.).

Durante esta etapa, se desarrollan en la costa norte las sociedades Lambayeque o Sicán y Chimú, mientras en la costa sur, florece la sociedad Ica-Chincha. Entre ambas áreas se establece el estilo Ychsma que fue anexado al imperio 
del Tahuantinsuyo por el Inca Cápac Yupanqui hacia los años 1460-1470 d. C. (Córdova, 2005: 207).

Los ychsma se extendieron en la costa central, zona geográfica que comprende los valles de los ríos Chillón, Rímac y Lurín localizados en la región Lima. Este territorio fue centro de intercambio e influencia regional siendo aprovechado por los locales que desarrollaron una identidad propia.

Algunos investigadores indican que la orfebrería en la costa central alcanzó un alto desarrollo, especialmente en trabajos de plata (Ríos \& Retamozo, 1978: 37; Vetter \& Villacorta, 2001: 205). Un grupo de plateros ychsma fue trasladado a la ciudad del Cusco por los incas que les dieron privilegios, mientras que otros se quedaron en sus valles al servicio de las elites locales (Espinoza, 1983; Vetter, 2008). Sus trabajos fueron parte importante del comercio local.

En contextos arqueológicos de los sitios de Rinconada, Isla San Lorenzo y Pachacamac reportaron un tipo de instrumento metálico llamado «paletas de calero» (Ministerio de Cultura, 2013: 66), «caleros» (Carcedo, 2000: 90-91), «cuchara para rape» (Carcedo \& Vetter, 2002:

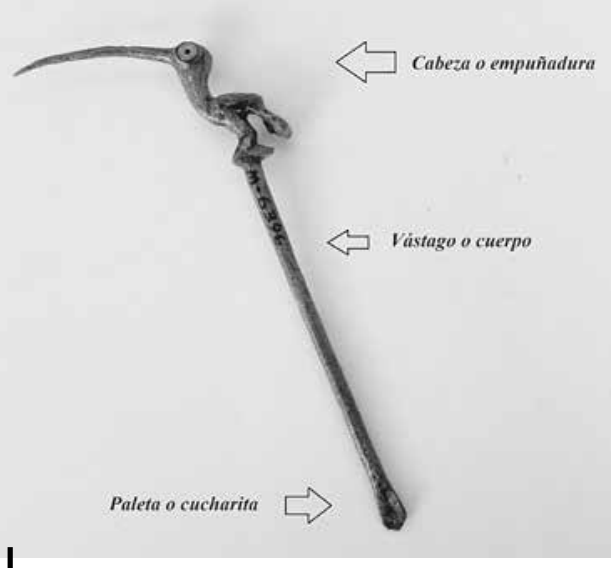

Figura 1 - Las tres partes en que se dividió la paleta de calero: cabeza o empuñadura, vástago o cuerpo y paleta o cucharita

(C) Luis Enrique Castillo, MNAAHP, 2015
60) o «limpia oídos» (Eaton, 1990 [1916]:19; Narváez, 1996: 105) que asocian al estilo incaico.

Este instrumento presenta una cucharita o paleta de forma ovalada que se asocia al uso de la cal en el consumo de la hoja de coca. Para una mejor comprensión, se ha dividido la paleta en tres partes: cabeza, vástago y paleta. La cabeza o empuñadura se ubica en la parte superior y presenta una iconografía variada. Se utilizaron de manera recurrente figuras ornitomorfas, donde las patas se posan sobre el vástago. El vástago o cuerpo es la zona que une la cabeza con la paleta. Por lo general tiene forma cilíndrica aunque tenemos casos de formas rectangulares. La paleta o cucharita, localizada en la parte inferior del vástago, presenta una terminación ovalada (fig. 1).

\section{CONTEXTOS ARQUEOLÓGICOS}

La expansión del imperio del Tawantinsuyo, el traslado de mitimaes y el sometimiento de las sociedades durante el Horizonte Tardío (1440-1532 d. C.) dieron una fusión de estilos en los Andes Centrales. La costa central no es ajena a este movimiento.

El Estado inca impuso cambios en la religión y la administración de las sociedades locales conquistadas. Durante esta etapa los sitios de Pachacamac, Armatambo, Maranga, Puruchuco y Huaycán de Cieneguilla, en la costa central, se convirtieron 
en centros administrativos y de acopio de materiales que distribuían de acuerdo a las directrices del Inca (Hudtwalcker, 2011: 114) transformándose en focos de intercambio y difusión cultural. El material cultural se transformó, cambiando la tipología e iconografía local por la foránea a la vez que se continuaba con las técnicas y materiales locales (fig. 2).

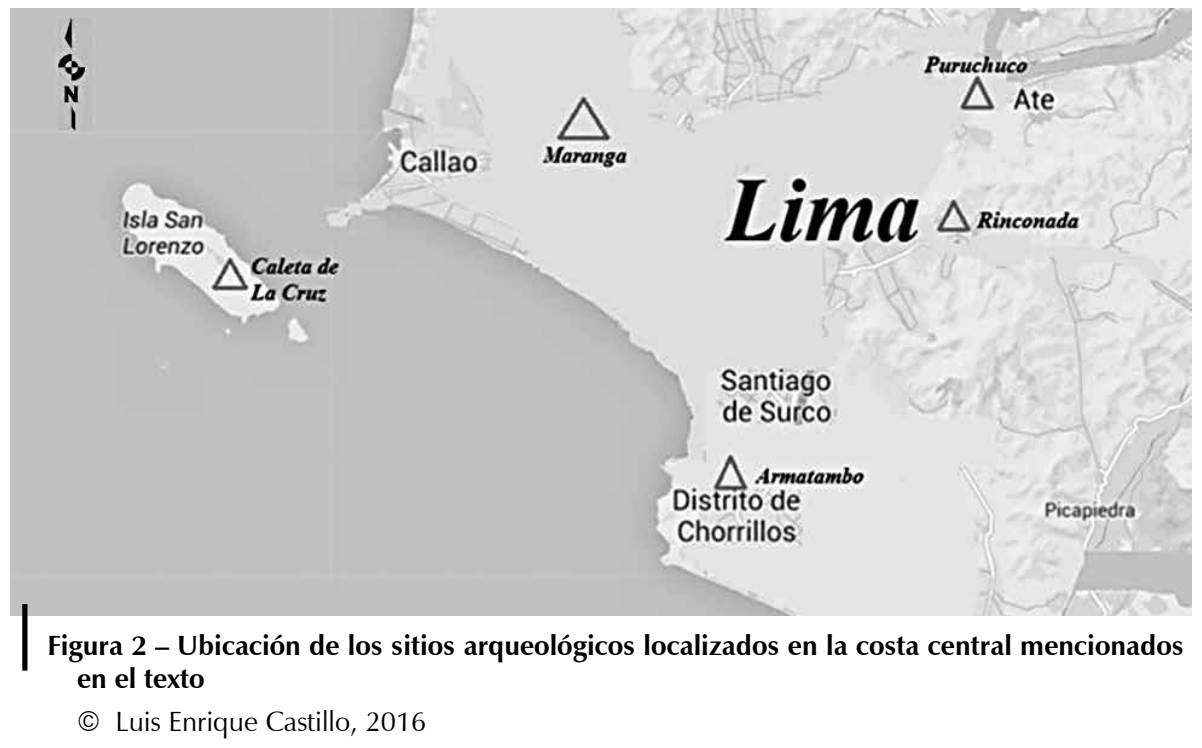

Los investigadores Luisa Díaz y Francisco Vallejos indican que artefactos como los textiles, caleros de metal y la concha Spondylus son recurrentes en los contextos funerarios de la costa central durante el Horizonte Tardío (Díaz \& Vallejo, 2005: 246). Las paletas de calero fueron reportadas en los sitios de Rinconada, Armatambo, Caleta de La Cruz y Pachacamac en la costa central y Túcume en la costa norte, lugares que presentan ocupación durante el Periodo Intermedio Tardío y el Horizonte Tardío. Algunos investigadores señalan que estos artefactos se asocian con el consumo de la hoja de coca (Dolmatoff, 1988; Pineda, 2005: 20; Vetter, 2011: 233).

En los Andes, los vocablos quechua Chaqchar, piqchar o aullicar significan: acto de masticar coca. El chacchado es la acción de colocar las hojas de coca en la boca, presionar con los dientes y humedecerlas con la saliva formando un bolo. Para que se pueda extraer de este bolo de coca las sustancias activas y estimulantes, se debe agregar la llipta o toqra, que es una mezcla de cal con cenizas vegetales o de conchas marinas; estos ingredientes varían de acuerdo al lugar. Para aplicar la llipta al bolo, se emplea un instrumento (paleta de calero) previamente humedecido con saliva, en el momento de introducirlo en el calero. Hay comunidades que preparan la llipta en una mezcla sólida y puede ser consumida directamente (mordiendo) (Esteva, 1971). 
Se conoce actualmente este instrumento como palito, palillo (Delgado, 1997: 16) o punzón metálico (Borrovic, 2006: 21); por lo general tiene la forma de una punta roma o sin filo. Esta punta se humedece para ser introducida en los caleros o recipientes que contienen las lliptas.

En el depósito de la colección de metales del Museo Nacional de Arqueología, Antropología e Historia del Perú (MNAAHP) se custodia una colección de paletas de calero obtenidas mediante investigaciones arqueológicas de los sitios de Rinconada, Isla San Lorenzo y Armatambo. Estos artefactos forman parte de esta investigación y su descripción se encuentra en el Anexo 1.

\section{1. Rinconada}

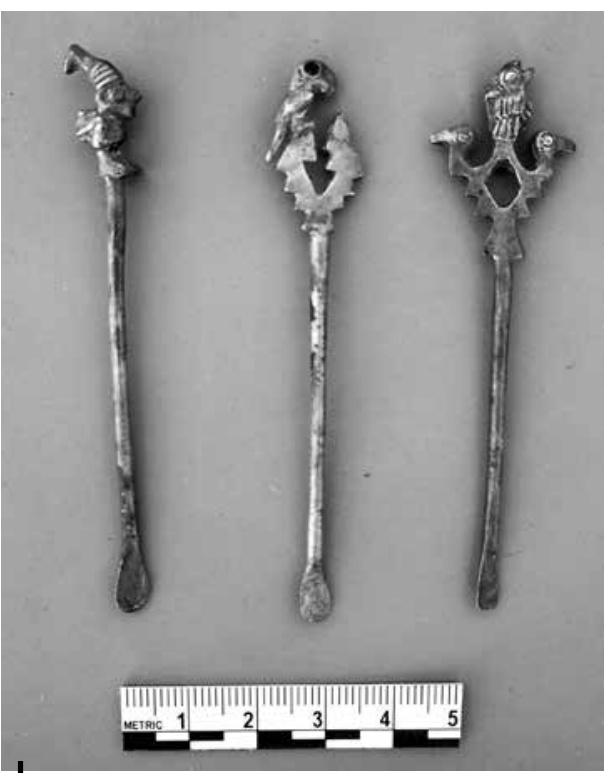

Figura 3 - Paletas de calero M-6384, M-1183 y M-1185 (izquierda a derecha), encontradas durante las excavaciones efectuadas por Max Uhle en los años 1906 y 1907 en el sitio arqueológico de Rinconada de Ate

(C) Luis Enrique Castillo, MNAAHP, 2015
El sitio arqueológico de Rinconada, también conocido con los nombres de Rinconada de Ate y Rinconada de La Molina, se localiza actualmente en el distrito de La Molina (departamento de Lima); sitio donde se realizaron proyectos arqueológicos con la finalidad de investigar la zona.

Las primeras excavaciones del lugar fueron efectuadas por Max Uhle en los años 1906 y 1907 con el fin de incrementar las colecciones del Museo de Historia Nacional. Logró obtener tres paletas de calero (M-1183; M-1185, M-6384) (fig. 3).

En las excavaciones realizadas por el Patronato Nacional de Arqueología en 1958 a cargo de la sección de Exploraciones, que realizó el reconocimiento arqueológico de los terrenos de la Compañía Urbanizadora Inmobiliaria Agrícola S.A. Rinconada La Molina, reportaron tres paletas de calero ( M-3593, M-3594, M-3595)

La tumba 72 corresponde a un fardo rectangular, perteneciente a un individuo femenino en posición de cuclillas, rellenado con hojas y fibra de algodón. Presenta amarres de soguilla asociados a una bolsa o chuspa (RM/373) de tipo listado cosido con hilo marrón. Dentro de la bolsa se reportó el RM/377 (M-3594), paleta de calero de cabeza esferoidal y dos pinzas (M-3620, M-3626); estos bienes fueron elaborados en aleación de plata. Al parecer las piezas estaban unidas por una «pita de cabuya» y asociadas a otros elementos culturales.

Lamentablemente no contamos con la información de campo de los caleros M-3593 (figura ornitomorfa, colibrí, elaborada en aleación de cobre) y M-3595 
(figura geométrica estilizada, elaborada en aleación de cobre) recuperados en la misma temporada del proyecto (fig. 4).

En la intervención realizada por el Proyecto Arqueológico de Rinconada Alta a cargo de Daniel Guerrero entre 1996 y 1998 en el sector IIA, se recuperaron 150 entierros dispuestos en tumbas circulares. Se hallaron cuatro paletas de calero, instrumentos y moldes para el trabajo orfebre (Carcedo \& Vetter, 2002: 47-49).

En el contexto 731 del S.IIA correspondiente a un fardo de individuo masculino disturbado se encontraron tres bolsas o chuspas. Dos de las chuspas no presentan decoración de algodón (RA 731) y una bolsa confeccionada con urdimbres de algodón, la cual presenta una decoración de bandas verticales de colores marrón claro, crema (RA 731.1), y en cuyo interior se ubicó una paleta de calero con figura ornitomorfa (M-9961) elaborada en aleación de cobre con estaño, un cuchillo (M-9957), un cincel de mango de cacho tallado (M-9958), esferas, pesas y fragmentos de metal (M-9962, M-9959, M-9960).

La paleta de calero con figura de un mono (M-9952),

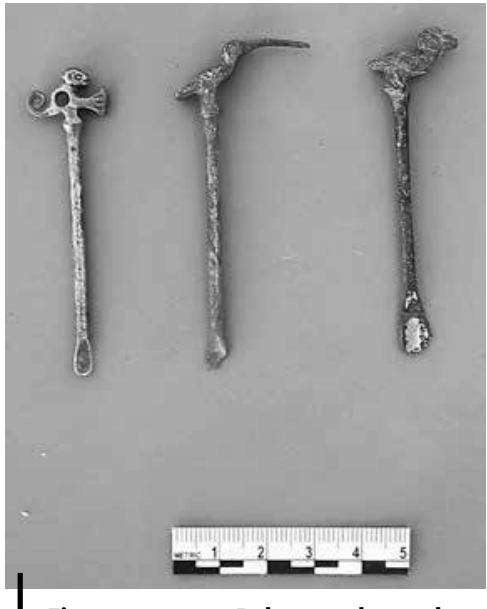

Figura 5 - Paletas de calero M-9952, M-9961 y el M-9972 (izquierda a derecha) reportadas por las excavaciones realizadas por Daniel Guerrero entre los años 1996-1998 en el sitio arqueológico de Rinconada Alta

(C) Luis Enrique Castillo, MNAAHP, 2015

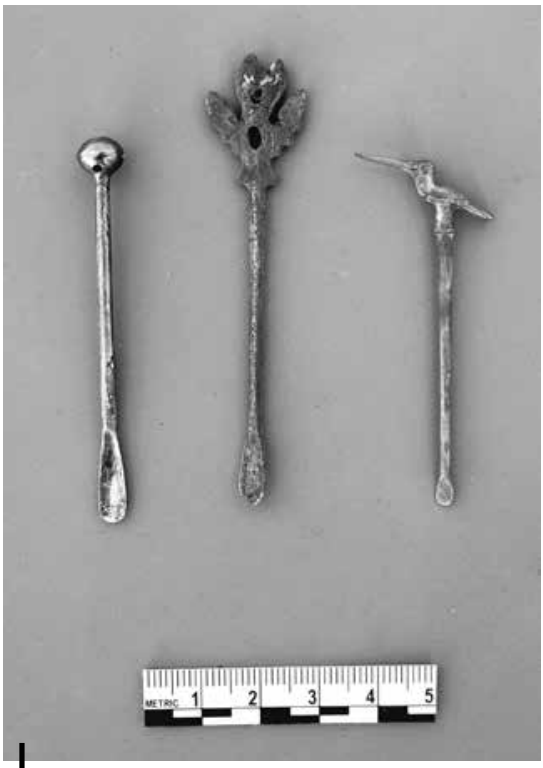

Figura 4 - Paletas de calero M-3593, M-3594, M-3595 (izquierda a derecha), encontradas durante las investigaciones del Patronato Nacional de Arqueología en 1958 en el sitio arqueológico de Rinconada de La Molina

(C) Luis Enrique Castillo, MNAAHP, 2015 plata, se recuperó en una tumba circular del contexto 803 correspondiente a un entierro disturbado.

En otro entierro disturbado perteneciente al contexto 892, se hallaron dos niños y dos adultos asociados a una paleta de calero con una figura ornitomorfa ( $M$ 9972), loro, manufacturado con aleación de cobre con estaño, tres pinzas $(M-10311)$ y fragmentos de metal (M-10311d). (fig. 5).

\section{2. Isla San Lorenzo}

Localizada frente a las costas del Callao (Lima) y a $5 \mathrm{~km}$ de la península de la Punta (Provincia constitucional del Callao), cuenta con ocupación durante el Periodo Intermedio Tardío y el Horizonte Tardío. El cementerio prehispánico más importante se denomina «Caleta de la Cruz», y está localizado en la zona sureste de la isla. Este sitio fue investigado por el Museo Nacional a cargo del Dr. Max Uhle en el año 1906; se hallaron varias vasijas, 


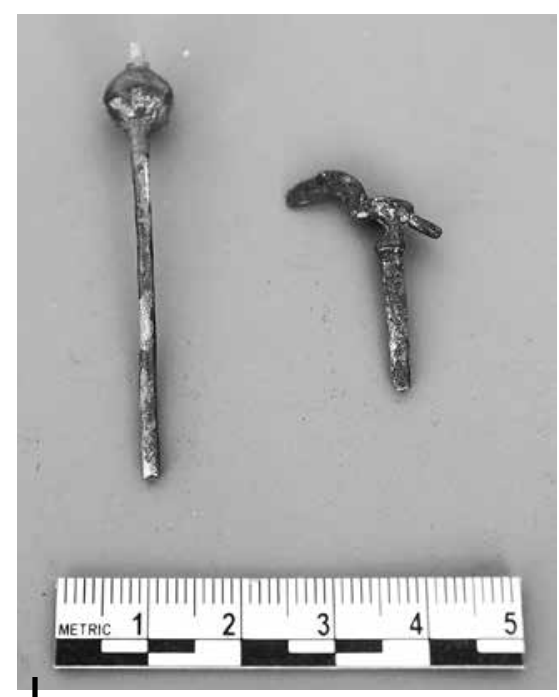

Figura 6 - Fragmentos de paletas de calero de plata $\mathrm{M}-1184$ y $\mathrm{M}-\mathbf{1 1 8 7}$ (izquierda a derecha) recuperadas en el cementerio prehispánico de «La Caleta de La cruz» localizado en la Isla San Lorenzo en 1906

(C) Luis Enrique Castillo, MNAAHP, 2015

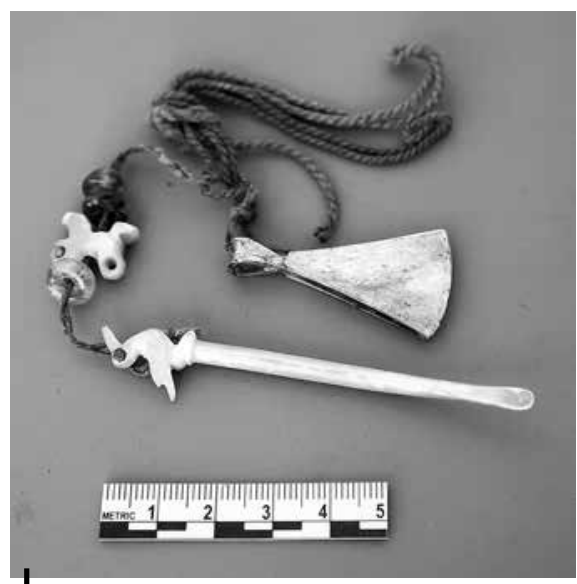

Figura 7 - Paleta de calero M-10557 reportada en las excavaciones realizadas por Luisa Díaz en 1992 en el sitio arqueológico de Armatambo

(C) Luis Enrique Castillo, MNAAHP, 2015 entre las que destacan vasos narigones elaborados en aleación de plata y dos paletas de calero (Ríos \& Retamozo, 1978: 4) (fig. 6).

\section{3. Armatambo}

Armatambo es un sitio arqueológico ubicado en la ladera oriental del Morro Solar en el distrito de Chorrillos (Lima). Se afirma que fue la sede principal del curacazgo de Surco o Sulco (Hyslop \& Mujica, 1992) perteneciente a la cultura Ychsma (Rostorowski, 1978: 56). Las excavaciones realizadas por el Proyecto de rescate arqueológico AAHH. San Pedro y 22 de octubre a cargo de la lic. Luisa Díaz en 1992, reportó una paleta de calero unida a una pinza (M-10557) (Díaz \& Vallejo, 2002: 370), asociada a dos anillos con decoración cincelada, a dos anillos sin decoración (M-10556; M-10551), a una pinza trapezoidal (M-10556) y a cuatro (04) bolsitas (fig. 7).

\section{4. Pachacamac}

Este sitio se ubica en la margen derecha del río Lurín, muy cerca del océano Pacífico y en el Km 31 de la Panamericana Sur, en el distrito de Lurín de la ciudad de Lima.

En 2012 el Museo de sitio de Pachacamac realizó trabajos de conservación en la plaza de los peregrinos, detectando pilares y un muro enlucido con hornacinas en las cercanías del ushno. Dentro del relleno se reportó una paleta de calero con figura zoomorfa (mono) sosteniendo un fruto (RNI173461). Esta paleta de calero es muy similar al M-9952.

En la exposición de dicho museo de sitio se exhiben cinco paletas de calero de aleaciones de plata, procedentes del sitio arqueológico de Pachacamac (fig. 8).

Sabemos que el Museo Etnográfico de Berlín en Alemania conserva una colección de paletas de calero procedentes de Pachacamac (Ministerio de Cultura, 2012: 71). 


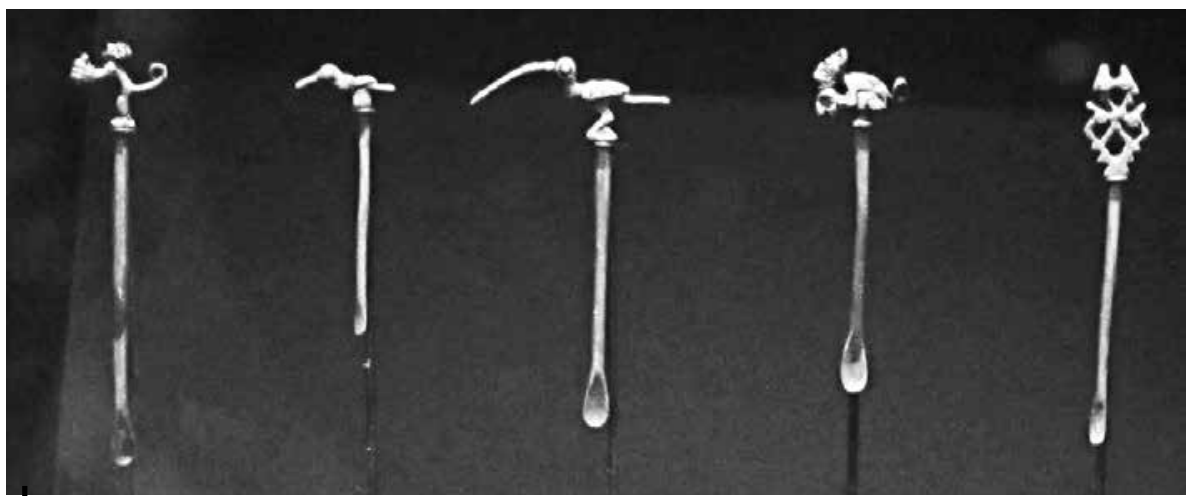

Figura 8 - Paletas de calero RNI 173461, RNI 144426, RNI 117128, RNI 117143, RNI 173480 (izquierda a derecha) encontradas en 2012 en el santuario arqueológico de Pachacamac

(C) Luis Enrique Castillo, MNAAHP, 2015

\section{5. Otros hallazgos realizados en la costa central}

En la Huaca de La Luz I, se recuperó una paleta de calero con figura ornitomorfa de pico largo de cobre y otra de cabeza de ave picoteando un pez elaborado en aleación de plata y otra de cobre procedente de Huaca Palomino (Vetter, 2011: 233) .

\section{6. Otros hallazgos realizados en la zona sur}

En la colección de metales del MNAAHP se cuenta con dos paletas de calero que provienen de la zona sur del Perú.

En 1912, la expedición de la Universidad de Yale y la Sociedad Geográfica Nacional a cargo de Hiram Bingham en la ciudadela de Machu Picchu (Cusco) reportaron 107 tumbas ubicadas en cuevas. En las laderas de la montaña de Machu Picchu se descubrió una terraza de abrigo rocoso al sureste de la ciudad donde se exhumaron las tumbas 23 y 26 . El material excavado en la tumba 26 corresponde a un individuo femenino acompañado de vasijas de cerámica, tupus, espejo, pinza, dos paletas de calero de bronce y agujas de espina (Eaton, 1990 [1916]: 19).

Las paletas de calero de Machu Picchu fueron elaboradas en aleación de cobre, una de ellas presenta una figura ornitomorfa en pleno vuelo y la otra presenta una cabeza esférica con vástago cilíndrico aguzado (muy similar a las reportadas por Uhle en Rinconada e Isla San Lorenzo).

En la costa norte, en la región de Lambayeque, las investigaciones arqueológicas realizadas en el marco del proyecto Túcume, en 1990, estuvieron a cargo de Alfredo Narváez quien excavó en la zona monumental el Cuarto 1 de la plataforma 2 de la Huaca Larga, reportando un fardo funerario masculino de alto rango. Las ofrendas de este contexto estaban constituidas por cerámicas, entre las que destacan un aríbalo y una botella con gollete y asa estribo de color negro así como 
ollas, calabazas pirograbadas, utensilios de madera, textiles decorados, mantos de plumas, tocado rojo con borla y metales.

Los metales de Túcume están conformados por una corona, orejeras y un pectoral elaborados en plata; fueron encontrados in situ. Un tumi de aleación de cobre, dos cuentas pulidas, dos paletas de calero y dos pinzas de plata se localizaron en la pelvis derecha. Las pinzas y las paletas de calero estaban envueltas juntas en telas de algodón (Narváez, 1996: 102).

Una de las paletas presenta una figura ornitomorfa, un colibrí, en posición de perfil y la otra representa un ave de cuello largo asociada a una pinza ovalada.

\section{ANÁLISIS ARQUEOMÉTRICOS}

Los análisis arqueométricos son imprescindibles para el conocimiento de materiales, de la tecnología y del estado de conservación de los bienes culturales. Siendo nuestro objetivo el de caracterizar las paletas de calero, se determinó emplear la arqueometría, utilizando técnicas de microscopía óptica, microanálisis y estudios radiográficos. Para tal fin, se seleccionaron doce paletas de calero procedentes de Rinconada, Isla San Lorenzo y Armatambo que presentan contextos y asociaciones de carácter arqueológico. Como primera directriz se elabora una ficha de registro, donde se anotan y fotografían las características físicas y tipológicas de cada objeto. Los análisis se realizaron en el laboratorio de conservación de metales del MNAAHP que cuenta con equipos de microscopios y rayos X. Para el estudio de microscopía óptica se empleó un estéreo microscopio de marca Olympus, modelo SZ60, que logra alcanzar un aumento de 200 x. La imagen es obtenida por reflexión, mostrando con mayor detalle la superficie de la muestra. Se complementa el estudio con la aplicación de solventes adecuados para la identificación de los metales.

Se tomaron muestras de seis paletas (M-1183, M-3595, M-3594, M-9952, M-9961 y M-9972), extraídas de la corrosión superficial. Los análisis fueron efectuados por la ingeniera química América Ramírez Céspedes, quien identificó aleaciones de plata y cobre que han sido afectadas por procesos corrosivos (Cuprita, carbonato de cobre, sulfuro y cloruro de plata y cobre). Los resultados obtenidos confirman la información sobre las aleaciones empleadas en la fabricación de las paletas: M-3594 y M-9952 son de plata y M-1183, M-3595, M-9961 y M-9972 son de cobre. Todas se encuentran alteradas por procesos de corrosión.

El laboratorio de conservación de metales del MNAAHP cuenta con un equipo de rayos X de marca Hitex Type HX-150 que permite percibir las estructuras internas, no visibles directamente o con otros medios. Cada uno de los bienes en estudio fue sometido a una limpieza superficial mediante hisopos de algodón embebidos en alcohol de $96^{\circ}$ para eliminar agentes superficiales que puedan distorsionar la toma de placas radiográficas. Se lograron identificar dos tipos de procesos de elaboración.

Uno, donde se emplea la técnica del vaciado y martillado específicamente para las paletas de calero de cabezas con representación de figuras ornitomorfas (M- 
3593, M-9961, M-9972, M-1187, M-10785, M-10886), zoomorfas (M-9952), antropomorfas (M-6384) y geométricas (M-1183; M-1185; M-3595). Y otro, donde el proceso de manufactura combina las técnicas de trefilado, laminado, embutido, recortado y soldadura con las cuales los artesanos trabajaron las paletas de calero con cabeza esférica y de vástago cilíndrico (M-3594, M-1184) (figs. 9, 10).

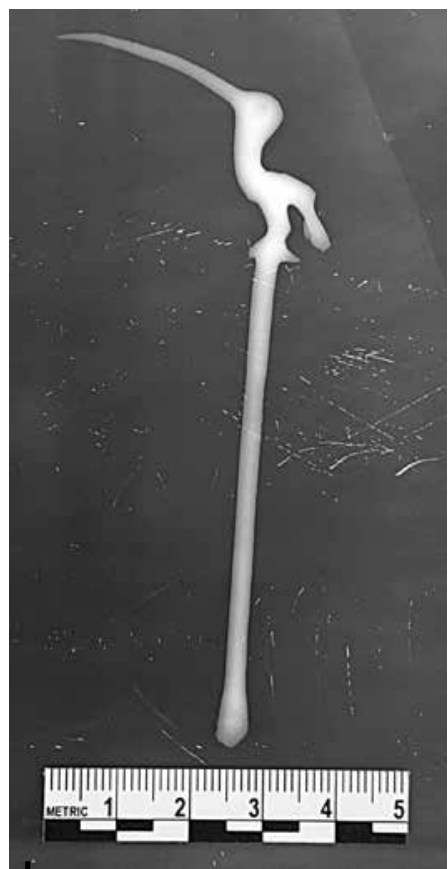

Figura 9 - Radiografía de la paleta de calero de cabeza ornitomorfa M-9961

(C) Luis Enrique Castillo, MNAAHP, 2015

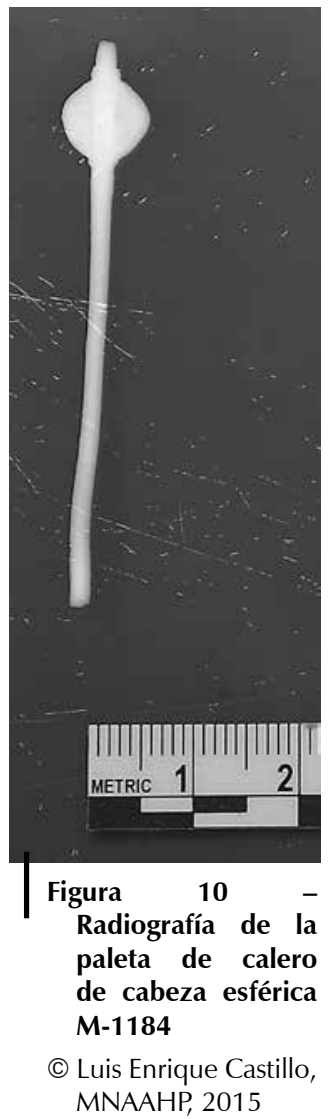

MNAAHP, 2015

\section{TECNOLOGÍA DE MANUFACTURA Y DE DECORACIÓN DE LAS PALETAS DE CALERO}

Los resultados de los alcances obtenidos gracias a la arqueometría indican que se usó plata y cobre como metales, así como dos técnicas de manufactura en las paletas de calero. Las cabezas de las paletas de calero están conformadas por figuras de cuatro tipos (ornitomorfa, zoomorfa, antropomorfa y geométrica) que se pueden ver en el anexo 2. 
Uno de estos procesos orfebres consistió en utilizar moldes de arcilla para el vaciado o colada para verter el metal y formar la cabeza y el vástago de las paletas. Posteriormente los orfebres eliminaban los rebordes y el material sobrante mediante diferentes procesos de cortado, limado, pulido y retoque. En el sitio de Rinconada, en el sector II A, investigado por Daniel Guerrero, se reportaron moldes de cerámica para el vaciado o colada. Estos moldes muestran evidencia de uso, están incompletos y presentan oscurecimiento en los bordes. Uno de ellos presenta la impronta de un ave de pico largo (M-9975) y el otro muestra el vástago tubular con la impronta de una parte de figura ornitomorfa (M-9976). Las investigaciones de Vetter (2013) sobre el molde M-9975 evidencian el empleo de vaciado y de plata. Es posible que estos moldes se hayan utilizado para manufacturar las paletas de calero ornitomorfas que se reportaron en el sitio (figs. $11,12)$.

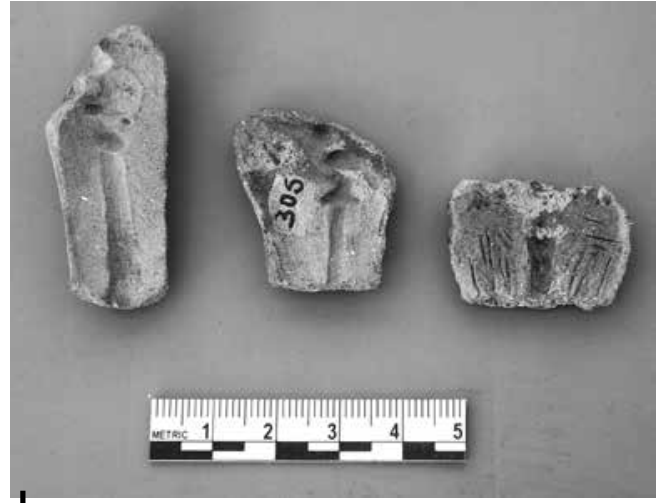

Figura 11 - Moldes de cerámica para el vaciado o colada M-9476, M-9975 y M-9977 (izquierda a derecha) encontrados en el sitio arqueológico de Rinconada Alta, sector II A.

(C) Luis Enrique Castillo, MNAAHP, 2015

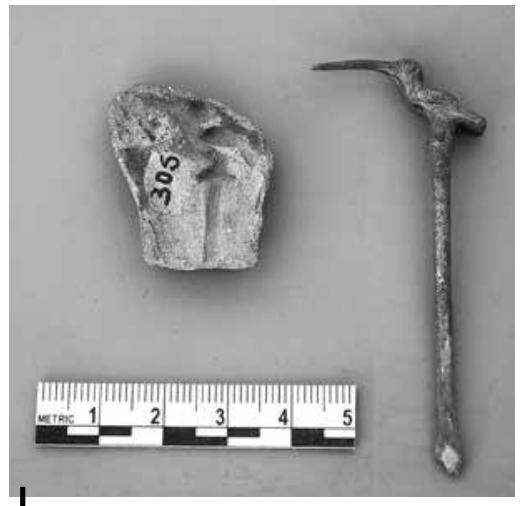

Figura 12 - Molde para el vaciado M-9975 y paleta de calero M-9961 (izquierda a derecha) reportados en la zona IIA del sitio de Rinconada Alta

(C) Luis Enrique Castillo, MNAAHP, 2015

Otro de los procesos de manufactura de la cabeza de la paleta de calero fue el empleo del embutido con la soldadura para formar una esfera que es perforada por un vástago trefilado cilíndrico. Este conjunto de métodos se utilizó en el M-3594 y el M-1184.

Para realizar la paleta o cucharita se martilla el extremo del vástago, intercalando con el recalentamiento (recocido); de esta manera el artesano evita que la lámina se fracture. El recocido es un método térmico que elimina las tensiones internas desarrolladas por la deformación plástica, aumentando la plasticidad, la ductilidad y la tenacidad del metal.

Estos artefactos muestran una perforación que se inserta en el cuerpo de la figura, por donde atraviesa un hilo. Los desgastes en la perforación evidencian que se trabajó mediante un punzón. El acabado se efectúo de acuerdo a las necesidades 
de cada pieza, en algunas figuras se emplearon cinceles de puntas finas que remarcaron las líneas incisas en el metal, destacando los detalles de las figuras.

\section{TRATAMIENTO DE CONSERVACIÓN}

La finalidad del tratamiento fue estabilizar los productos corrosivos y destacar los detalles de las paletas de calero para poder presentarlas como parte de una exhibición temporal del museo. Estos objetos proceden de contextos ubicados en la costa central del Perú. Por lo tanto fueron recuperados en un ambiente alcalino, debido a la cercanía del mar, lo que acrecentó su deterioro. Los metales tienden a protegerse mediante la formación de patinas, que oscurecen las capas superficiales, debido a procesos internos y externos como la humedad y los cambios de temperatura. Por lo tanto, las corrosiones se inician protegiendo al metal más noble del medioambiente. En el caso particular de las paletas de calero presentan cuprita, carbonato de cobre, sulfuros y cloruros de plata y cobre.

Los procedimientos a nivel de conservación estuvieron acorde con las necesidades de cada bien cultural. Para cada pieza se realizó una limpieza superficial con pinceles y cepillos de cerdas suaves; posteriormente se empleó alcohol de $96^{\circ}$ aplicado con hisopos de algodón mecánicamente, eliminando el polvo y los agentes extraños a la composición de los metales.

Para evitar que nuevamente las paletas de calero de cobre formen corrosiones por los procesos internos electroquímicos, se efectuó la inhibición mediante compresas de algodón en una solución de Benzotriazole (BTA) al 2\% en etanol. Para finalizar el tratamiento se eliminó la solución por inmersión en etanol. La precipitación del BTA sobre el cloruro cuproso forma una barrera contra cualquier humedad que podría activar el cloruro de cobre (Madsen, 1967). Por lo tanto el BTA forma una capa pasiva con el cobre, insoluble en disoluciones acuosas y orgánicas; por ende inhibe la corrosión, evitando la degradación del núcleo metálico.

Tras nuestra evaluación, se acordó por necesidad realizar un contenedor ensamblado por unión mecánica elaborado con láminas extruida en polipropileno y con espuma de polietileno donde se almacenan las paletas de calero. Este contenedor no empleó ningún tipo de adhesivo para evitar las emanaciones de gases que pueden ocurrir durante el almacenaje. Los bienes se encuentran rotulados y cubiertos con papel de seda y albergados en el depósito de la colección de metales del MNAAHP.

\section{CONCLUSIONES PRELIMINARES}

Durante el Horizonte Tardío, solo las elites incas y posiblemente los mensajeros o chasquis que recorrían el Qhapaq Ñan podían consumir hojas de coca. Se afirma que el consumo de la hoja de coca servía para mitigar el hambre y la sed; por añadidura da fuerza y vigor al poblador andino. Por lo tanto y para esta época, la práctica del chacchado estuvo restringida a usos con fines sociales, religiosos, medicinales y adivinatorios. 
El análisis de las asociaciones de las paletas de calero en los contextos arqueológicos nos hace dudar de su uso como instrumento para aplicar la cal en el bolo de coca durante el chacchado. En este periodo, en el valle del Chillón, se localizaban plantaciones (Rostworoski, 2004: 269) que posiblemente suministraban coca para el consumo de las elites locales, lo cual fue motivo de disputas entre esferas de poder. Incluso se ha recuperado cal y coca en tumbas pertenecientes al Horizonte Tardío de sitios costeros como la necrópolis de Ancón (Ravines \& Stothert, 1978). Debido a la falta de artefactos como las lliptas y las hojas de coca en los entierros de Rinconada, Armatambo e Isla San Lorenzo, es factible pensar que las paletas no fueron creadas para este fin.

A través del análisis arqueométrico y comparativo de las paletas de calero podemos indicar que a nivel tecnológico, el empleo de aleaciones de plata y de cobre es recurrente en este tipo de instrumentos, así como el empleo de moldes de arcilla para el vaciado en la fabricación de las cabezas de figuras escultóricas y de vástagos. Se excluye las que presentan esferas que se trabajaron en láminas recortadas, embutidas y soldadas al vástago cilíndrico.

La meticulosidad del orfebre se evidencia en los tratamientos superficiales de los metales. Podemos observar que las figuras en las paletas exponen un fino acabado y detalle en la representación iconográfica; por esta razón, consideramos que se apreciaron de cerca. Dicho de otro modo, estarían relacionadas con la ingesta de alucinógenos. Sin embargo se debe ahondar en mayores estudios para caracterizar los rituales chamánicos.

La distribución y adquisición de los metales y sus respectivas aleaciones estuvieron restringidas por los incas. Las crónicas e investigadores asocian la plata con la mitología de deidades femeninas como la diosa Luna para el mundo andino y el Urpayhuachac (la que pare palomas) en la costa central. Los contextos funerarios estudiados develan datos interesantes. Los individuos masculinos se relacionan con figuras ornitomorfas especialmente el colibrí, constituidos por aleaciones de plata y los individuos femeninos con figuras esféricas construidos en aleaciones de cobre. Conviene destacar que la figura ornitomorfa tendría afinidad con la costumbre de ingerir alucinógenos, descartando el nexo entre el ave y la deidad Urpayhuachac. Ponemos de ejemplo que para las culturas colombianas prehispánicas, el ave se relaciona con el vuelo chamánico y la trasmutación del hombre en la deidad.

En cuanto a los temas iconográficos representados en las paletas también se plasman en otros soportes como la cerámica y la textilería del Horizonte Tardío.

\section{Agradecimientos}

Un agradecimiento muy especial a la Dra. Luisa Vetter y a la Lic. Diana Fernández por su colaboración, apoyo, paciencia y sus consejos para realizar esta investigación. Gracias a su constante aporte científico y amistad, he logrado caracterizar las paletas de calero de la costa central durante el Horizonte Tardío. Asimismo deseo agradecer a las Dras. María Filomena Guerra y Paz Núñez-Regueiro por darme la oportunidad de colaborar con esta investigación sobre orfebrería prehispánica durante el Horizonte Tardío. 


\section{Referencias citadas}

BORROVIC, F., 2006 - Efecto antibacteriano del extracto alcohólico de la hoja de Erythroxylum Novogranatense var. truxillense (сосa) sobre flora mixta salival. Tesis para optar el Título profesional de Cirujano Dentista, 87 pp.; Lima: Universidad Nacional Mayor de San Marcos.

CARCEDO, P., 2000 - Plata, transformación en el arte precolombino del Perú, 120 pp.; Lima: Patronato de Plata del Perú.

CARCEDO, P. \& VETTER, L., 2002 - Instrumentos utilizados para la fabricación de piezas de metal para el período Inca. Baessler Archiv, 50: 47-66.

CORDOVA, M., 2005 - El Sauce, un cementerio del Horizonte Tardío en San Juan de Lurigancho, Lima. Corriente Arqueológica, 1: 199-221.

DELGADO, H., 1997 - Cuaderno de bitácora: el uso de la Coca en el Mundo Andino, 40 pp.; Lima: Ministerio de Salud.

DÍAZ, L. \& VALLEJO, F., 2002 - Armatambo y el dominio incaico en el valle de Lima. Boletín de Arqueología PUCP, n. ${ }^{\circ}$ 6: 355-374.

DÍAZ, L. \& VALLEJO, F., 2005 - Clasificación del patrón funerario Ychsma identificado en Armatambo y la Rinconada Alta. Corriente Arqueológica, 1: 223-322.

DOLMATOFF, R., 1988 - Orfebrería y chamanismo: Un estudio iconográfico del Museo de Oro, 174 pp.; Bogotá: Banco Central de Reserva.

EATON, G. F., 1990 [1916] - La colección del material osteológico de Machu Picchu, 151 pp.; Lima: Sociedad de Arqueología Andina, Embajada de Estados Unidos de América. Traducción y edición de Sonia Guillén Oneeglio.

ESPINOZA, W., 1983 - Los Mitmas plateros de Ishma en el país de los Ayamarca siglos XVXIX. Boletín de Lima, 30: 38-52.

ESTEVA, C., 1971 - Los usos de la coca en Chinchero, Cuzco (Perú). MUNIBE, XXIII (4): 429-443.

HYSLOP, J. \& MUJICA, E., 1992 - Investigaciones de A. F. Bandelier en Armatambo (Surco). Gaceta Arqueológica Andina, Vol. VI n. ${ }^{\circ}$ 22: 63-86.

HUDTWALCKER, J., 2011 - Chaupiñamca y el baile del Casayaco: alcances preliminares del estudio iconográfico del manto pintado encontrado por Max Uhle en la isla San Lorenzo. Revista Arqueología y Sociedad de la Universidad Nacional Mayor de San Marcos, 23: 93-132.

MADSEN, H. B., 1967 - A preliminary note on the use of benzotriazole for stabilising bronze objects. Studies in conservation, 12: 153-166.

MINISTERIO DE CULTURA, 2012 - Obras maestras en la colección del Museo de Sitio de Pachacamac, 76 pp.; Lima: Ministerio de Cultura del Perú.

MINISTERIO DE CULTURA., 2013 - Manual de procedimientos en el sistema de registro del patrimonio cultural de la Nación, 78 pp.; Lima: Dirección de Museos y Bienes Muebles del Ministerio de Cultura del Perú.

NARVÁEZ, A., 1996 - Las pirámides de Túcume, el sector monumental. In: Túcume (Thor Heyerdahl, ed.): 83-152; Lima: Banco de Crédito del Perú.

PINEDA, R., 2005 - El laberinto de la identidad: Símbolos de transformación y poder en la orfebrería prehispánica de Colombia. In: Oro de Colombia, chamanismo y orfebrería: 17-91; Bogotá: Museo de Arte Precolombino Chileno.

RAVINES, R. \& STOTHERT, S., 1978 - Un entierro común del Horizonte Tardío en la costa central del Perú. Revista del Museo Nacional, tomo XLII: 153-206. 
RíOS, M. \& RETAMOZO, E., 1978 - Objetos de metal procedentes de la isla de San Lorenzo, 98 pp.; Lima: Ministerio de Cultura, Museo Nacional de Antropología y Arqueología.

ROSTWOROWSKI, M., 1978 - Señoríos indígenas de Lima y Canta, 281 pp.; Lima: Instituto de Estudios Peruanos.

ROSTWOROWSKI, M., 2004 - Costa peruana prehispánica, 376 pp.; Lima: Instituto de Estudios Peruanos.

VETTER, L., 2008 - Plateros indígenas en el virreinato del Perú: siglos XVI y XVII, 292 pp.; Lima: Fondo Editorial de la Universidad Nacional Mayor de San Marcos, Compañía de Minas Buenaventura S.A.A.

VETTER, L., 2011 - Las Huacas Pando: un acercamiento a la orfebrería precolombina del valle de Rímac, Perú. In: Arqueología Peruana, homenaje a Mercedes Cárdenas (L. Vetter, S. Téllez \& R. Vega-Centeno, eds.): 207-245; Lima: Instituto Riva-Agüero.

VETTER, L., 2013 - El platero indio en los Andes: siglos XVI y XVII; Lima: Pontificia Universidad Católica del Perú. Tesis para optar el grado académico de Doctora en Historia con mención en Estudios Andinos.

VETTER, L. \& VILLACORTA L. F., 2001 - La arqueometalurgía de la costa central del Perú: Una perspectiva desde la colección del Museo de Sitio Arturo Jiménez BorjaPuruchuco. Baessler Archiv, 49: 193-210.

\section{ANEXOS}

\section{ANEXO 1 - PALETAS DE CALERO}

\begin{tabular}{|c|c|c|c|c|c|c|}
\hline \multicolumn{7}{|c|}{ Sitio Rinconada } \\
\hline Código & Foto & Tipo & $\begin{array}{l}\text { Metal / } \\
\text { Aleación }\end{array}$ & $\begin{array}{l}\text { Objetos } \\
\text { asociados }\end{array}$ & $\begin{array}{l}\text { Técnica de } \\
\text { elaboración }\end{array}$ & $\begin{array}{l}\text { Investigadores } \\
\text { y año }\end{array}$ \\
\hline M-6384 & & $\begin{array}{l}\text { Figura } \\
\text { antropo- } \\
\text { morfa } \\
\text { portando } \\
\text { tocado y } \\
\text { cargando } \\
\text { cilindro }\end{array}$ & Cobre & No presenta & $\begin{array}{l}\text { Vaciado, } \\
\text { martillado, } \\
\text { perforado. }\end{array}$ & Uhle, 1906 \\
\hline M-1183 & & $\begin{array}{l}\text { Loro sobre } \\
\text { figura } \\
\text { geométrica }\end{array}$ & cobre & No presenta & $\begin{array}{l}\text { Vaciado, } \\
\text { martillado, } \\
\text { perforado. }\end{array}$ & Uhle, 1906 \\
\hline
\end{tabular}




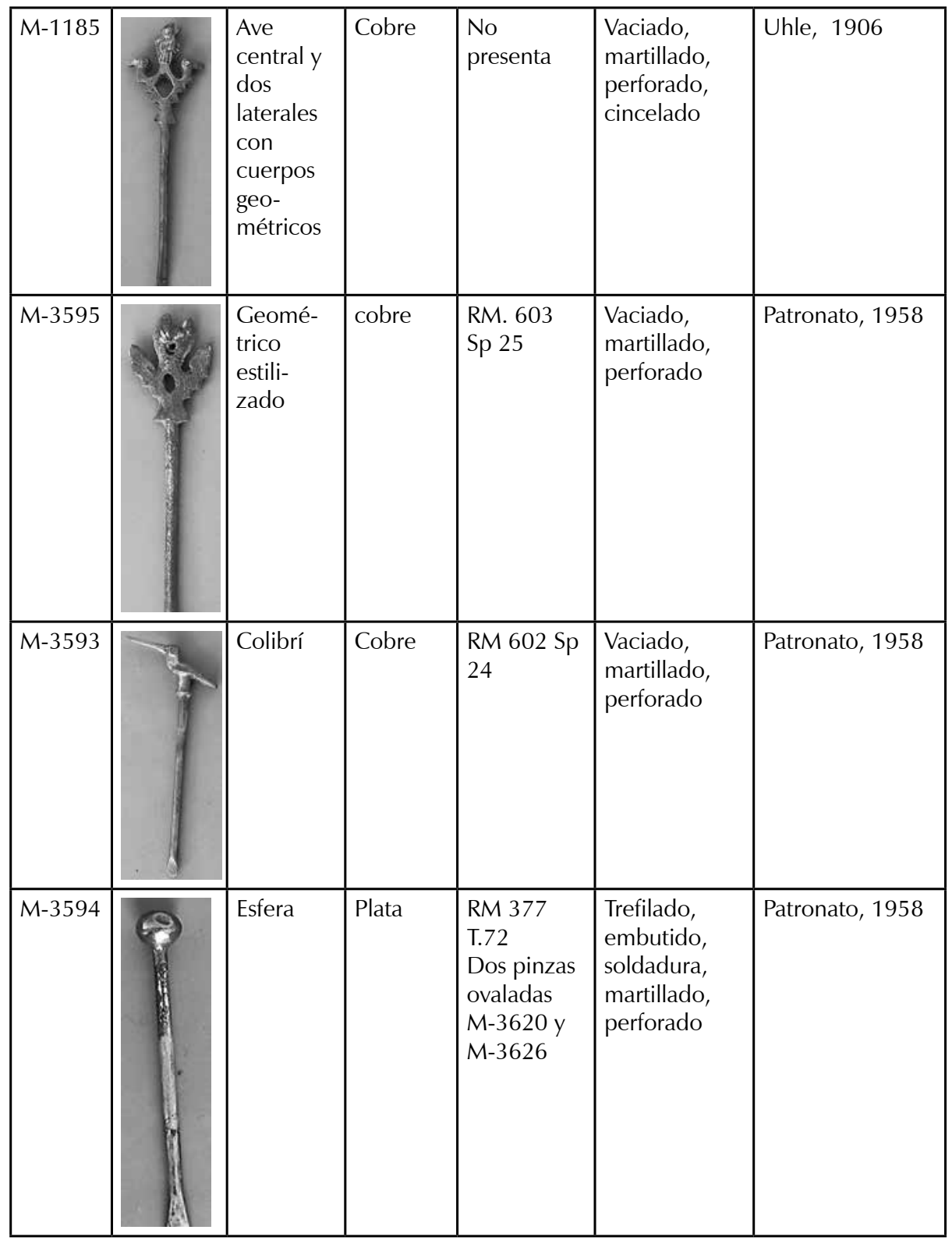


Las paletas de calero de la costa central durante el Horizonte Tardío (1440-1532 d. C.)

\begin{tabular}{|c|c|c|c|c|c|c|}
\hline M-9961 & q & Colibrí & Cobre & $\begin{array}{l}731 \text { IIA } \\
\text { Rinconada } \\
\text { Alta. Cincel } \\
\text { M-9958, } \\
\text { Tumi } \\
\text { M-9957; } \\
\text { esferas, } \\
\text { pesas } \\
\text { M-9962 }\end{array}$ & $\begin{array}{l}\text { Vaciado, } \\
\text { martillado, } \\
\text { perforado }\end{array}$ & Guerrero, 1997 \\
\hline M-9952 & $\frac{20}{20}$ & $\begin{array}{l}\text { Mono } \\
\text { soste- } \\
\text { niendo } \\
\text { fruto }\end{array}$ & Plata & $\begin{array}{l}803 \text { IIA } \\
\text { Rinconada } \\
\text { Alta. Fardo } \\
\text { disturbado }\end{array}$ & $\begin{array}{l}\text { Vaciado, } \\
\text { martillado, } \\
\text { perforado }\end{array}$ & Guerrero, 1997 \\
\hline M-9972 & 893 & Loro & Cobre & $\begin{array}{l}892 . \\
\text { Rinconada } \\
\text { Alta tres } \\
\text { pinzas } \\
\text { trapezoi- } \\
\text { dales } \\
\text { M-10311 }\end{array}$ & $\begin{array}{l}\text { Vaciado, } \\
\text { martillado, } \\
\text { perforado }\end{array}$ & Guerrero, 1997 \\
\hline
\end{tabular}




\section{Sitio Caleta de la Cruz. Isla San Lorenzo}

\begin{tabular}{|l|l|l|l|l|l|l|}
\hline Código & Foto & Tipo & $\begin{array}{l}\text { Metal/ } \\
\text { Aleación }\end{array}$ & $\begin{array}{l}\text { Objetos } \\
\text { asociados }\end{array}$ & $\begin{array}{l}\text { Técnicas de } \\
\text { elaboración }\end{array}$ & $\begin{array}{l}\text { Investiga- } \\
\text { dores y año }\end{array}$ \\
\hline M-1187 & Ave & Plata & $35 / 3337$ & $\begin{array}{l}\text { Vaciado, } \\
\text { perforado }\end{array}$ & Uhle, 1906 \\
& & & & & & \\
\hline
\end{tabular}

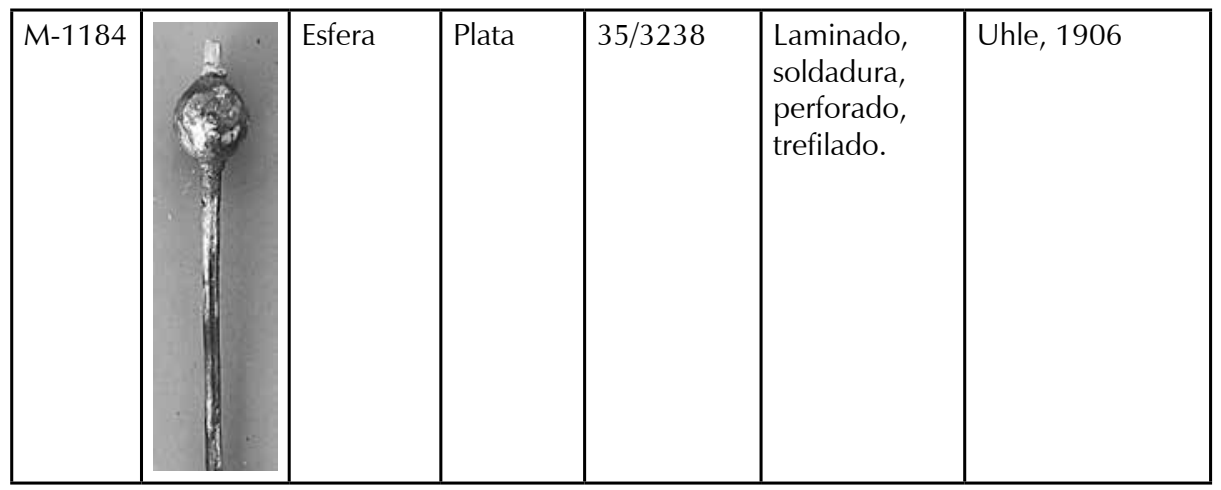

\begin{tabular}{|l|l|l|l|l|l|l|}
\hline \multicolumn{2}{|l|}{ Sitio Armatambo } & Tipo & $\begin{array}{l}\text { Metal/ } \\
\text { Aleación }\end{array}$ & $\begin{array}{l}\text { Objetos } \\
\text { asociados }\end{array}$ & $\begin{array}{l}\text { Técnicas de } \\
\text { elaboración }\end{array}$ & $\begin{array}{l}\text { Investiga- } \\
\text { dores y año }\end{array}$ \\
\hline Código & Foto & Ave & $\begin{array}{l}\text { Concha } \\
\text { nácar y } \\
\text { aplica- } \\
\text { ción } \\
\text { crisocola } \\
\text { en el ojo }\end{array}$ & $\begin{array}{l}\text { Pinza } \\
\text { trapezoidal } \\
\text { de plata, } \\
\text { tres cuentas } \\
\text { de cristal } \\
\text { verde, } \\
\text { cuenta } \\
\text { zoomorfa } \\
\text { de concha }\end{array}$ & $\begin{array}{l}\text { Tallado y } \\
\text { aplicado }\end{array}$ & Díaz, 1992 \\
& & & & \\
\hline
\end{tabular}




\begin{tabular}{|c|c|c|c|c|c|c|}
\hline \multicolumn{7}{|c|}{ Sitio Pachacamac } \\
\hline Código & Foto & Tipo & $\begin{array}{l}\text { Metal / } \\
\text { Aleación }\end{array}$ & $\begin{array}{l}\text { Objetos } \\
\text { asociados }\end{array}$ & $\begin{array}{l}\text { Técnicas de } \\
\text { elaboración }\end{array}$ & \begin{tabular}{|l|}
$\begin{array}{l}\text { Investiga- } \\
\text { dores y año }\end{array}$ \\
\end{tabular} \\
\hline $\begin{array}{l}\text { RNI } \\
173461\end{array}$ & & $\begin{array}{l}\text { Mono } \\
\text { soste- } \\
\text { niendo } \\
\text { fruto }\end{array}$ & Plata & $\begin{array}{l}\text { Relleno } \\
\text { cerca del } \\
\text { Ushno. } \\
\text { Plaza los } \\
\text { Peregrinos }\end{array}$ & $\begin{array}{l}\text { Vaciado, } \\
\text { martillado, } \\
\text { perforado }\end{array}$ & $\begin{array}{l}\text { Proyecto de } \\
\text { conser- } \\
\text { vación, } 2002\end{array}$ \\
\hline $\begin{array}{l}\text { RNI } \\
117128\end{array}$ & & Colibrí & Plata & $\begin{array}{l}\text { No } \\
\text { presenta }\end{array}$ & $\begin{array}{l}\text { Vaciado, } \\
\text { martillado, } \\
\text { perforado }\end{array}$ & $\begin{array}{l}\text { Ministerio de } \\
\text { Cultura, } 2012\end{array}$ \\
\hline $\begin{array}{l}\text { RNI } \\
144426\end{array}$ & & $\begin{array}{l}\text { Ave con } \\
\text { ojos } \\
\text { redon- } \\
\text { deados }\end{array}$ & Plata & $\begin{array}{l}\text { No } \\
\text { presenta }\end{array}$ & $\begin{array}{l}\text { Vaciado, } \\
\text { martillado, } \\
\text { perforado }\end{array}$ & $\begin{array}{l}\text { Ministerio de } \\
\text { Cultura, } 2012\end{array}$ \\
\hline $\begin{array}{l}\text { RNI } \\
117143\end{array}$ & 8 & $\begin{array}{l}\text { Dos } \\
\text { aves con } \\
\text { diseño } \\
\text { estilizado }\end{array}$ & Plata & $\begin{array}{l}\text { No } \\
\text { presenta }\end{array}$ & $\begin{array}{l}\text { Vaciado, } \\
\text { martillado, } \\
\text { perforado }\end{array}$ & $\begin{array}{l}\text { Ministerio de } \\
\text { Cultura, } 2012\end{array}$ \\
\hline
\end{tabular}




\begin{tabular}{|l|l|l|l|l|l|}
\hline $\begin{array}{l}\text { RNI } \\
173480\end{array}$ & $\begin{array}{l}\text { Felino } \\
\text { soste- } \\
\text { niendo } \\
\text { cabeza }\end{array}$ & Plata & $\begin{array}{l}\text { No } \\
\text { presenta }\end{array}$ & $\begin{array}{l}\text { Vaciado, } \\
\text { martillado, } \\
\text { perforado }\end{array}$ & $\begin{array}{l}\text { Ministerio de } \\
\text { Cultura, } 2012\end{array}$ \\
& & & & & \\
\hline
\end{tabular}

\begin{tabular}{|c|c|c|c|c|c|c|}
\hline \multicolumn{7}{|c|}{ Sitio Túcume } \\
\hline Código & Foto & Tipo & $\begin{array}{l}\text { Metal/ } \\
\text { Aleación }\end{array}$ & $\begin{array}{l}\text { Objetos } \\
\text { asociados }\end{array}$ & $\begin{array}{l}\text { Técnicas de } \\
\text { elaboración }\end{array}$ & $\begin{array}{l}\text { Investiga- } \\
\text { dores y año }\end{array}$ \\
\hline & & Colibrí & $\begin{array}{l}\text { Plata } \\
\text { con } \\
\text { cobre }\end{array}$ & $\begin{array}{l}\text { Huaca } \\
\text { Larga. } \\
\text { Cerámica } \\
\text { Inca, Dos } \\
\text { pinzas de } \\
\text { plata }\end{array}$ & $\begin{array}{l}\text { Vaciado, } \\
\text { martillado, } \\
\text { perforado }\end{array}$ & Narváez, 1990 \\
\hline & & $\begin{array}{l}\text { Ave de } \\
\text { cuello } \\
\text { largo }\end{array}$ & $\begin{array}{l}\text { Plata } \\
\text { con } \\
\text { cobre }\end{array}$ & $\begin{array}{l}\text { Huaca } \\
\text { Larga. } \\
\text { Cerámica } \\
\text { Inca, Dos } \\
\text { pinzas de } \\
\text { plata }\end{array}$ & $\begin{array}{l}\text { Vaciado, } \\
\text { martillado, } \\
\text { perforado }\end{array}$ & Narváez, 1990 \\
\hline
\end{tabular}

\begin{tabular}{|l|l|l|l|l|l|l|}
\hline \multicolumn{2}{|l|}{ Sitio Machu Picchu } \\
\hline Código & Foto & Tipo & $\begin{array}{l}\text { Metal/ } \\
\text { Aleación }\end{array}$ & $\begin{array}{l}\text { Objetos } \\
\text { asociados }\end{array}$ & $\begin{array}{l}\text { Técnicas de } \\
\text { elaboración }\end{array}$ & $\begin{array}{l}\text { Investiga- } \\
\text { dores y año }\end{array}$ \\
\hline & & Ave & cobre & $\begin{array}{l}\text { Entierro } \\
\text { femenino } \\
26, \text { tupus, } \\
\text { espejo } \\
\text { y pinza } \\
\text { trapezoidal } \\
\text { Vaciado, } \\
\text { martillado, } \\
\text { perforado }\end{array}$ & Bingham, 1912 \\
& & & & & \\
& & & & & & \\
\hline
\end{tabular}


Las paletas de calero de la costa central durante el Horizonte Tardío (1440-1532 d. C.)

\begin{tabular}{|l|l|l|l|l|l|}
\hline & Esfera & Cobre & $\begin{array}{l}\text { Entierro } \\
\text { femenino } \\
\text { 26, tupus, } \\
\text { espejo } \\
\text { y pinza } \\
\text { trapezoidal } \\
\text { martillado, } \\
\text { perforado }\end{array}$ & $\begin{array}{l}\text { Baciado, } \\
\text { mam, }\end{array}$ \\
\hline
\end{tabular}

\begin{tabular}{|c|c|c|c|c|c|c|}
\hline \multicolumn{7}{|c|}{ Huaca La Luz y Palomino } \\
\hline Código & Foto & Tipo & $\begin{array}{l}\text { Metal / } \\
\text { Aleación }\end{array}$ & $\begin{array}{l}\text { Objetos } \\
\text { asociados }\end{array}$ & $\begin{array}{l}\text { Técnicas de } \\
\text { manufactura }\end{array}$ & $\begin{array}{l}\text { Investiga- } \\
\text { dores y año }\end{array}$ \\
\hline & & Colibrí & $\begin{array}{l}\text { Plata } \\
\text { con } \\
\text { cobre }\end{array}$ & $\begin{array}{l}\text { Desco- } \\
\text { nocido }\end{array}$ & $\begin{array}{l}\text { Vaciado, } \\
\text { martillado, } \\
\text { perforado }\end{array}$ & $\begin{array}{l}\text { Ramos de Cox } \\
1968\end{array}$ \\
\hline & & $\begin{array}{l}\text { Ave } \\
\text { picote- } \\
\text { ando } \\
\text { pez }\end{array}$ & $\begin{array}{l}\text { Plata } \\
\text { con } \\
\text { cobre }\end{array}$ & $\begin{array}{l}\text { Desco- } \\
\text { nocido }\end{array}$ & $\begin{array}{l}\text { Vaciado, } \\
\text { martillado, } \\
\text { perforado }\end{array}$ & $\begin{array}{l}\text { Ramos de Cox } \\
1968\end{array}$ \\
\hline
\end{tabular}


Luis Enrique Castillo Narrea

\begin{tabular}{|l|l|l|l|l|l|l|}
\hline & $\begin{array}{l}\text { Ave pico- } \\
\text { teando } \\
\text { pez }\end{array}$ & cobre & $\begin{array}{l}\text { Desco- } \\
\text { nocido }\end{array}$ & $\begin{array}{l}\text { Vaciado, } \\
\text { martillado, } \\
\text { perforado }\end{array}$ & $\begin{array}{l}\text { Ramos de Cox } \\
1968\end{array}$ \\
\end{tabular}

\begin{tabular}{|l|l|l|l|l|l|l|}
\hline \multicolumn{2}{|l|}{ Inca uyu } & Tipo & $\begin{array}{l}\text { Metal/ } \\
\text { Aleación }\end{array}$ & $\begin{array}{l}\text { Objetos } \\
\text { asociados }\end{array}$ & $\begin{array}{l}\text { Técnicas } \\
\text { de manu- } \\
\text { factura }\end{array}$ & $\begin{array}{l}\text { Investigadores } \\
\text { y año }\end{array}$ \\
\hline $\begin{array}{l}\text { M- } \\
10785\end{array}$ & Foto & Cóndor & cobre & $\begin{array}{l}\text { Inca uyu } \\
\text { (Puno). } \\
\text { Desco- } \\
\text { nocido }\end{array}$ & $\begin{array}{l}\text { Vaciado, } \\
\text { perforado }\end{array}$ & Rowe 1942 \\
\hline
\end{tabular}

\begin{tabular}{|l|l|l|l|l|l|l|}
\hline \multicolumn{2}{|l|}{ Chincha } & Tipo & $\begin{array}{l}\text { Metal/ } \\
\text { aleación }\end{array}$ & $\begin{array}{l}\text { Objetos } \\
\text { asociados }\end{array}$ & $\begin{array}{l}\text { Técnicas de } \\
\text { manu- } \\
\text { factura }\end{array}$ & $\begin{array}{l}\text { Investigadores } \\
\text { y año }\end{array}$ \\
\hline $\begin{array}{l}\text { M- } \\
10886\end{array}$ & Foto & $\begin{array}{l}\text { Ave de } \\
\text { perfil con } \\
\text { alas en } \\
\text { forma de } \\
\text { olas }\end{array}$ & cobre & $\begin{array}{l}\text { Desco- } \\
\text { nocido }\end{array}$ & $\begin{array}{l}\text { Vaciado, } \\
\text { martillado, } \\
\text { perforado }\end{array}$ & Desconocido \\
\hline
\end{tabular}

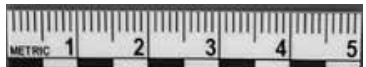


Las paletas de calero de la costa central durante el Horizonte Tardío (1440-1532 d. C.)

ANEXO 2 - ICONOGRAFÍA DE LOS CALEROS

\begin{tabular}{|c|c|c|c|c|}
\hline Tipo & Procedencia & $\begin{array}{l}\text { Material / } \\
\text { Aleación }\end{array}$ & Códigos & Contexto \\
\hline Colibrí & Pachacamac & Plata & RNI 117128 & Desconocido \\
\hline Colibrí & Rinconada & Cobre & M-3593 & Desconocido \\
\hline Colibrí & Rinconada & Cobre & M--9961 & Masculino \\
\hline Colibrí & Túcume & Plata & & Masculino \\
\hline Colibrí & Huaca La Luz I & Plata & & Desconocido \\
\hline Cóndor & Inca Uyu & & M-10785 & Desconocido \\
\hline Loro & Rinconada & Cobre & M-9972 & Disturbado \\
\hline $\begin{array}{l}\text { Loro con } \\
\text { figura } \\
\text { geométrica }\end{array}$ & Rinconada & Cobre & M-1183 & Desconocido \\
\hline Ave & Isla San Lorenzo & Plata & $M-1187$ & Desconocido \\
\hline Ave & Armatambo & Concha & M-10557 & Disturbado \\
\hline Ave & Pachacamac & Plata & RNI-144426 & Desconocido \\
\hline Ave & Túcume & Plata & & Masculino \\
\hline Ave & Machu Picchu & Cobre & & Femenino \\
\hline \multirow{2}{*}{$\begin{array}{l}\text { Ave } \\
\text { picoteando } \\
\text { pez }\end{array}$} & Huaca La Luz I & Plata & & Desconocido \\
\hline & $\begin{array}{l}\text { Huaca } \\
\text { Palomino }\end{array}$ & Cobre & & Desconocido \\
\hline $\begin{array}{l}\text { Ave de perfil } \\
\text { con alas en } \\
\text { forma de olas }\end{array}$ & Chincha & Cobre & M-10886 & Desconocido \\
\hline $\begin{array}{l}\text { Mono } \\
\text { sosteniendo } \\
\text { fruto }\end{array}$ & Rinconada & Plata & M-9952 & Disturbado \\
\hline $\begin{array}{l}\text { Mono } \\
\text { sosteniendo } \\
\text { fruto }\end{array}$ & Pachacamac & Plata & RNI-173461 & $\begin{array}{l}\text { Relleno. Plaza de } \\
\text { los Peregrinos }\end{array}$ \\
\hline $\begin{array}{l}\text { Felino } \\
\text { sosteniendo } \\
\text { cabeza }\end{array}$ & Pachacamac & Plata & RNI-173480 & Desconocido \\
\hline $\begin{array}{l}\text { Ave central } \\
\text { con dos aves } \\
\text { de cuerpos } \\
\text { geométricos }\end{array}$ & Rinconada & Plata & M-1185 & Desconocido \\
\hline
\end{tabular}


Luis Enrique Castillo Narrea

\begin{tabular}{|l|l|l|l|l|}
\hline $\begin{array}{l}\text { Diseño } \\
\text { estilizado } \\
\begin{array}{l}\text { con dos aves } \\
\text { de cuerpo } \\
\text { geométrico }\end{array}\end{array}$ & Pachacamac & Plata & RNI-117143 & Desconocido \\
\hline $\begin{array}{l}\text { Geométrico } \\
\text { estilizado }\end{array}$ & Rinconada & Cobre & M-3595 & Desconocido \\
\hline Esfera & Rinconada & Plata & M-3594 & Femenino \\
\hline Esfera & Isla San Lorenzo & Plata & M-1184 & Desconocido \\
\hline Esfera & Machu Picchu & Cobre & & Femenino \\
\hline $\begin{array}{l}\text { Figura } \\
\text { antropomorfa }\end{array}$ & Rinconada & Cobre & M-6384 & Desconocido \\
\hline
\end{tabular}

